not appear to hear. There was also a weak infrequent cough.

On the following day (the 20 th) he had perfect movement in the respiratory muscles, though the breathing was slow, and there was a little wheezing on the left side. Temperature subnormal.

Nov. 27th.-Respiration 16 ; pulse 52; temperature $966^{\circ}$. Abdominal reflexes nearly absent; tache cerébrale present on the abdomen, and to a less extent on the chest; knee-jerks weak; ankle-clonus present; posterior nuuscles of the legs rigid.

28th.-The patient tells me he was last week doing lead casting in the course of his employment, and the day before his attack was mixing red and white lead. At tea on the 25 th he had shrimps, and it is probable that the action of the finger-tips in picking the shells off worked the lead from under the nails on to the fish, and, thus seasoned, he swallowed them, as he subsequently found lead under the nails. The gums showed the lead line well marked, and there was apparently no other source but the lead under the nails for the poison, as the lead was not tonched in the process of casting or afterwards, nor was any other person in the house affected.

The question remains, what was the immediate cause of the pardysis and of its rapid disappearance? Shock alone would not account for it, because the pupils were not dilated, as is always the case, I believe; nor was the cutaneous circulation altered, nor would the small dose of morphia have had such widespread and permanent effect on the sympathetic. The course the pain took was that of the stomach and cesophagus; this indicates implication of the pneumogastric nerve. The symptoms and the result of the treatment confirm this view. To take the last first The improvement in respiration and pulse can be accounted for if, looking upon the case as one of inhibition of the respiratory centre by the vagus, we remember that atropine injected in even the smallest doses has the power of pre venting this inhibitory action of the racus. Indeed, this was what first gave me a clue to a rational explanation of the observed phenomena. The inhibition was no doubt set up by excessive stimulation of the gastric terminal branches transmitted to the central ending of the nerve by its main trunks, and through the respiratory centre could have caused the slowing of the heart; this was very considerable, if the rate of the breathing is compared with it, the usual proportions being reversed. The temporary paralysis of the palate might be accounted for by regarding it as part of the respiratory system. The known unequal excitability of the branches of the vagus might account for the absence of change in the voice. The continuance of action of the phrenic nerve on the right side can only be accounted for by supposing that the respiratory centre was unequally affected. I foroot to say that soon after the pain ceased the urine was passed; a later sample showed nierely excess of phosphates and urea. The amoun was slightly in excess of the normal quantity. The bowels were confined on the day following the attack. My remarks are based on the third edition of Landois and Stirling and on Foster's text-books.

Queen's-crescent, N.W

\section{Clinical ates:}

\section{MEDICAL, SURGICAL, OBSTETRICAL, AND THERAPEUTICAL.}

NOTE ON A

\section{POINT OF DIFFERENCE IN THE PATHOLOGY OF GOUTY AND RHEUMATOID ARTHRITIS.}

\section{BY E. T. WYNNE, M.B. CANTAB.}

HOLSE PHYSICIAN, ST. BARTHOLOMEW'S HOSPITAT.

THAT both these diseases produce deformities of joints is well known, and the deformities are described as due in the one case to deposition of urates, in the other to changes in the hard tissues of the joint. But there is a change in the bony structures of joints met with in many cases of articular gout which at first sirht would seem to bring these two diseases (formerly confounded, now clearly separated) into aser connexion with each other, but which I hope by my description to show really marks a new, and, if $\mathrm{my}$ inter pretation of the condition is correct, a radical difference between them. This change has been recognised and described before, but its nicroscopic characters have, I believe, never been carefully investigated. Cornil and Ranvier mention it roughly in their work on Pathology, but their description differs entirely from what I have myself found. The condition is best seen in the knee. On ex amining such a knee through the skin, the margins of the articular surfaces are felt to be more protuberant than natural; and on opening the joint the articular cartilage appears to have been squeezed out by pressure, so as to produce a "lip" or ridge around the margin. This lipping has a superficial resemblance to the condition seen in early rheumatoid arthritis, of ten described as a heaping up of the cartilage at the free margin. A closer examination shows radical differences. In rheumatoid arthritis such an outgrowth is found microscopically to consist of cartilage in a state of fibrillation, which may in parts be calcified, but which rarely shows ossification. I have examined microscopic specimens of extreme cases showing ossification ; but the outgrowth is found even in the most advanced cases to have a complete investment of cartilage. The outgrowth is therefore a chondroma produced by overgrowth of the articular cartilage. Now, looking at a specimen of gouty arthritis, the opalescent cartilage is seen to stop short at the summit of the outgrowth, and microscopic sections show the same. Such a section taken at the edge of the joint shows the cartilage healthy, except for senile changes, becoming a little thinner at its outer extremity, and ter minating at the summit of the protuberance, the rest of the outgrowth being covered with a thin layer of fibrous tissue, continuous with that of the periosteum and synovial mem brane. The outgrow th presents the appearance of a sprouting of the cancellous tissue of the epiphysis, carrying the car tilage before it. It is, in short, an exostosis. This condition is met with in joints the seats of uratic de posits, and in those showing erosions of the cartilage (probably formerly the seat of uratic deposits), accompanied by deposition of urates in other joints. I have examined a number of such joints, and have found the condition constant. I have never met with it in rheumatoid arthritis. In explanation of this difference between these two diseases, I would suggest that the outgrowths in rheumatoid arthritis are the result of a dystrophy of the joint-possibly of neurotic orimin,--whereas those of articular gout are the result of irritation, either from deposition of urates in the neighbourhood, or more probably from the circulation through the bone of blood containing an abnormal amount of urates. Whether this be the true explanation or not, the fact itself seems of sufficient interest for attention to be called to it.

St. Bartholomew's Hospital.

\section{RUPTURE OF FIBULAR TENDON OF BICEPS FEMORIS.}

By Ernest F. Neve, M.D., F.R.C.S.Ed.

K. M-, a male, aged about twenty-eight, on June 13th, 1885, whilst running across a field, felt a crack and some pain. He was able to limp home. When I saw him on the 14th, I could find no trace of the fibular tendon of the biceps on the right side. With the leg bent at right angles to the thigh, the posterior aspect of the head of the fibula could be distinctly felt, but the attachment of the tendon was not distinguishable. A slight swelling, painful on pressure, was felt at the postero-external aspect of the lower third of the thigh. Three inches above the npper border of the patella the circumference of the limb was increased by three quarters of an inch as compared with its fellow. On the 15th a portion of tendon two inches in length, freely mobile, conld be felt attached to the fibular head. The injury was treated by moderate flexion. The position was found by the patient to be very irksome. By the 25th the swelling had abated half an inch, and the tendon was beginning to stand out as a ridge; its sheath appeared thickened. On July 8 th there was no pain on manipulation, but a slight limp in walking, though the patient could walk a mile without discomfort. From this date the patient improved steadily for a time.

On March 21st, 1888, I had an opportunity of again 